\title{
Языковая политика Франции: исторический вектор развития
}

Михаил Марусенко

DOI: 10.30547/mediaalmanah.6.2020.168181

(c) Марусенко Михаил Александрович профессор Санкт-Петербургского государственного университета, главный научный сотрудник Российского государственного педагогического университета имени А.И. Герцена (г. Санкт-Петербург, Россия), mamikhail@yandex.ru
Язык всегда был для французов предметом культа, во многом определяющим их национально-культурную идентичность. «Язык - это основной признак нации, неосознанный шедевр национального сознания. На сегодняшний день французы не имеют дела важнее, чем дело их языка», утверждал известный французский лингвист Клод Ажеж. И он же отмечал, что ни одна страна не приняла больше законов, касающихся своего языка, чем Франция1. Эта тенденция прослеживается на протяжении всей истории Франции.

История французской языковой политики является предметом пристального научного интереса как российских лингвистов-романистов ${ }^{2}$, так и экспертов, в той или иной степени причастных к языковой политике. К сожалению, последние, не в полной степени знакомые с институциональными документами французской языковой политики, часто основывают свои высказывания на банальных и не соответствующих современной эпохе представлениях о французской языковой политике как о единой политике укрепления (доминирования) французского языка, главной задачей которой является борьба с англицизмами, в большом количестве внедряющимися во французский язык.

Основанием для таких высказываний служит поверхностное знакомство с историей 


\title{
La politique linguistique de la France : un vecteur historique du développement
}

\author{
Mikhaïl Maroussenko
}

\author{
(C) Maroussenko Mikhaïl \\ professeur, Université d'état de Saint-Pétersbourg. \\ Directeur de recherches, université pédagogique d'État Herzen. \\ (Saint-Pétersbourg, Russie), mamikhail@yandex.ru
}

Pour la France et les Français, la langue a toujours été un objet de culte, déterminant dans une large mesure leur identité nationale et culturelle. Claude Imbert, célèbre journaliste français qui se bat activement pour défendre la langue française, a fait valoir les arguments suivants : "La langue est le signe principal d'une nationalité [...] un chef-d'œuvre inconscient de la conscience nationale. Il n'est pas, aujourd'hui, de plus grande cause française que celle de sa langue ». Cette tendance se retrouve tout au long de l'histoire de France. Dans une interview accordée à la publication Label France Claude Hagège notait qu'aucun pays n'a adopté plus de lois concernant sa langue que la France 1 .

L'histoire de la politique linguistique française fait l'objet d'un intérêt scientifique soutenu tant de la part des linguistes russes spécialistes en langues romanes ${ }^{2}$ que des personnes plus ou moins impliquées dans la politique linguistique. Malheureusement, ces dernières, qui ne sont pas pleinement familiarisés avec les documents institutionnels de la politique linguistique française, font souvent reposer leurs déclarations sur des idées reçues et leurs opinions sur des conceptions de la politique linguistique française ne correspondant pas à notre époque, la présentant comme une politique unique de renforcement de la domination de la langue française dont la mission principale est de lutter contre l'introduction d'un grand nombre d'anglicismes dans la langue française.

Ces déclarations s'appuient sur une connaissance superficielle de l'histoire de la loi n 94-665 du 4 août 1994 relative à l'usage du français, mieux connue sous le nom de loi Toubon, bien que le ministre de la Culture de l'époque, Jacques Toubon, ait eu un rapport très indirect avec celle-ci : la loi avait été rédigée et soumise au Parlement sous la direction de la ministre de la Culture du gouvernement précédent Catherine Tasca. Comme cette loi est la dernière d'une série sur la langue française, on a l'habitude de considérer en Russie que la politique linguistique française se développe en stricte conformité avec ses dispositions.

L'histoire de la politique linguistique française peut être divisée en trois étapes, la première étant l'enracinement du français en tant que langue de l'État, langue officielle du pays et la diffusion du monolinguisme sur l'ensemble du territoire. La deuxième étape est la lutte contre la domination de l'anglais et les tentatives de faire retrouver à la langue française sa gloire et sa position d'antan dans le 
Закона № 94-665 от 4 августа 1994 г. об использовании французского языка, более известного как закон Тубона, хотя занимавший в тот момент пост министра культуры Жак Тубон имел к нему весьма косвенное отношение: закон готовился и вносился в парламент при прежнем правительстве, под руководством министра культуры Катрин Таска. Поскольку этот документ является последним по времени в серии французских языковых законов, в России считается, что французская языковая политика развивается строго в соответствии с его положениями.

Историю языковой политики Франции можно условно разделить на три этапа, первый из которых - это укоренение французского языка в качестве государственного официального языка страны и распространение моноязычия по всей территории государства. Вторым этапом стали борьба с доминированием английского языка и попытки вернуть французскому языку его былую славу и положение в мире. Сегодня мы переживаем третий этап, содержание которого в целом определяется положением Французской Республики как государства-члена Европейского союза. Как и во всех прочих областях, языковая политика государства-члена ЕС не может противоречить европейской языковой политике, формулируемой соответствующим еврокомиссаром.

От «Страсбургских клятв» и Ордонанса Вилле-Коттре до законов об обязательном бесплатном начальном образовании в эпоху Третьей республики Франция проделала тысячелетний путь к тому, чтобы французский из диалекта королевского домена превратился в родной язык для подавляющего большинства французов. Для этого во многом пришлось искоренить региональные языки и диалекты, чему особенно способствовала революция, а позднее наполеоновские реформы и армия, в которой представители различных регионов смешивались и поэтому были вынуждены использовать французский язык в качестве средства общения.

Третья республика (1870-1940) и особенно республиканская школа помогли завершить процесс франсизации страны: за 70 лет через школы прошло несколько поколений граждан, так что к 1940 г. французский язык был первым для всех. Помимо этого, Первая мировая война 1914-1918 гг. также перемешала в траншеях диалекты людей из разных регионов и вызвала волну патриотизма, сплотившую народ вокруг общего дела защиты Франции от агрессоров. К середине XX в. в стране не осталось граждан, не говоривших на французском.

Завершился первый этап языковой политики Франции, целью которой была франсизация населения. Внешнеполитическая расстановка сил изменилась после Второй мировой войны, в которой значительную роль сыграли Соединенные Штаты Америки. После войны они стали играть ведущую роль в мировой политике, что ознаменовало начало гегемонии англо-американского языка. Так начался второй этап языковой политики Франции, характеризующийся неравной борьбой с английским языком по всем направлениям, главным инструментом которой стал языковой пуризм. Переход к третьему этапу, вызванный необходимостью проведения общей языковой политики в рамках Европейского союза и приведший к резкому изменению языковой политики Франции, произошел во второй половине первого десятилетия XXI в.

Внутри Европейского союза членство Соединенного королевства и стран с сильной англофильской традицией (например, государства Северной Европы) ослабило роль французского как рабочего языка международного общения. Еще в 1961 г. Соединенные Штаты Америки и Великобритания приняли решение о внедрении и распространении английского языка в мире всеми возможными способами. При этом их не останавливало возможное сопротивление со стороны образовательных 
monde. Nous sommes aujourd'hui dans la troisième phase, conditionnée à la position de la France en tant qu'État membre de l'Union européenne. Comme dans tous les autres domaines, la politique linguistique d'un État membre de l'UE ne peut aller en contradiction avec la politique linguistique européenne formulée par le commissaire concerné.

Depuis les Serments de Strasbourg et l'ordonnance de Villers-Cotterêts jusqu'aux lois sur l'enseignement primaire obligatoire et gratuit sous la Troisième République, la France a parcouru un chemin millénaire de transformation du français de dialecte du domaine royal en langue maternelle de la grande majorité des Français, ce qui a largement nécessité l'élimination des langues et dialectes régionaux, phénomène particulièrement facilité par la Révolution et plus tard par les réformes napoléoniennes et l'armée dans laquelle les représentants des différentes régions étaient mêlés et donc contraints d'utiliser la langue française.

La Troisième République (1870-1940), et en particulier l'École républicaine, contribua à achever le processus de francisation du pays : en 70 ans, plusieurs générations de citoyens sont passées par les écoles, si bien qu'en 1940, le français était la première langue pour tous. De plus, la Première Guerre mondiale de 1914-1918 a également mêlé dans les tranchées les dialectes de différentes régions et a provoqué une vague de patriotisme qui a uni les gens autour d'une cause commune : la protection de la France contre les agresseurs. Au milieu du XXe siècle, il n'y avait plus aucun citoyen en France ne parlant pas français.

La première phase de la politique linguistique française, dont le but était de franciser la population, était arrivée à son terme. L'équilibre des forces en matière de politique étrangère changea après la Seconde Guerre mondiale au cours de laquelle les États-Unis d'Amérique jouèrent un rôle important. Après la guerre, ils acquirent un rôle de premier plan dans la politique mondiale, ce qui marqua le début de l'hégémonie de la langue anglo-américaine. Ainsi commence la deuxième phase de la politique linguistique française, caractérisée par une lutte inégale contre l'anglais dans toutes les directions, dont l'outil principal est le purisme linguistique. Le passage à la troisième phase, motivé par la nécessité d'une politique linguistique commune au sein de l'Union européenne et entraînant un changement radical de la politique linguistique française, a eu lieu dans la seconde moitié de la première décennie du XXle siècle.

Au sein de l'Union européenne, l'adhésion du Royaume-Uni et des pays à forte tradition anglophone (comme les États nordiques) affaiblit le rôle du français comme langue de travail dans les échanges internationaux. Dès 1961, les ÉtatsUnis et le Royaume-Uni décidèrent d'introduire et de diffuser l'anglais dans le monde entier de toutes les manières possibles, y compris de manière cachée, principalement en imposant l'anglais comme deuxième langue ou langue étrangère. En même temps, ils ne furent pas arrêtés par une éventuelle résistance des systèmes d'enseignement des pays qui étaient visés par cette politique.

Au fil du temps, des organisations dédiées à la préservation de la langue et de son statut commencèrent à émerger en France. Dès la présidence de Charles De Gaulle en 1966, le premier organisme interne de défense de la langue française fut mis en place : le « Haut comité pour la défense et l'expansion de la langue française ". Georges Pompidou, Premier ministre de De Gaulle, était conscient de la nécessité d'une action politique sur la langue française, qu'il incarna dans 
систем стран, являвшихся объектами такой политики.

Со временем во Франции начинают появляться организации, посвященные защите языка и его положения. Еще во время президентства Шарля де Голля в 1966 г. была учреждена первая внутригосударственная организация, занимавшаяся защитой французского языка, - Высший комитет по защите и распространению французского языка (Haut comité pour la défense et l'expansion de la langue française). Жорж Помпиду, премьер-министр во время правления де Голля, осознавал необходимость политических мер в отношении французского языка, что и воплотил в создании Высшего комитета ${ }^{3}$. Отметим, что Помпиду, филолог по образованию и выпускник Высшей нормальной школы, осознавал опасности для положения французского языка. Предвидел он и то, как вступление Великобритании в Европейский союз может оказать влияние на статус французского как языка международного общения, и даже обсуждал с британским премьер-министром Эдвардом Хитом вопросы подбора франкоговорящих чиновников для европейских учреждений, использования двух рабочих языков. Помпиду объяснял свое беспокойство тем, что английский язык уже в тот момент был не только языком Англии, но прежде всего языком США, что могло привести к потере европейской идентичности Европы и ее подчинению заокеанской державе ${ }^{4}$.

Создание Высшего комитета по защите и распространению французского языка стало прямой реакцией премьер-министра на книгу «Говорите ли вы на франгле?» (Parlez-vous franglais?) Рене Этьямбля, французского писателя и лингвиста, однокурсника Помпиду по Нормальной школе5. Вслед за Комитетом появились терминологические комиссии, чьей задачей являлся либо подбор терминов для обозначения новых реалий, либо подбор французского аналога для нежелательных заимствований в целях очищения языка6. Тем самым правительство выражало свое намерение борьбы с другим языком, под которым, естественно, подразумевается английский источник большинства заимствований.

Первый закон об использовании французского языка был принят при Президенте Валери Жискар д'Эстене, известном своими проанглийскими настроениями. 31 декабря 1975 г. был подписан закон № 75-1349 об использовании французского языка, более известный как закон Ба-Лориоля. Идея законопроекта принадлежит депутату Национальной ассамблеи Пьеру Ба, который выдвинул его в мае 1973 г., а в июне того же года доклад на эту тему подготовил другой депутат, Марк Лориоль. Рассмотрение документа пришлось отложить из-за кончины Жоржа Помпиду, так что подписывал его уже новый президент.

У закона Ба-Лориоля были две основные цели: во-первых, защита интересов потребителей, во-вторых, сохранение языкового единства, которое воспринималось как национальное и культурное наследие. Тем не менее ограничительные меры, вводимые этим законом в духе языкового пуризма, несколько противоречили идеям свободы потребителей и их интересов. В итоге создателей закона обвинили в неподобающем проявлении языкового национализма и излишнем желании контролировать язык. Вскоре после принятия закон был забыт и в дальнейшем практически не применялся, однако ретроспективно многие исследователи видят в нем рациональную меру по защите работников и потребителей

Во время президентства Франсуа Миттерана сформировалась активная группа депутатов, стремившихся усовершенствовать закон Ба-Лориоля и, в частности, расширить сферу его применения. Было выдвинуто множество законопроектов, из которых только проект, подготовленный министром культуры Катрин Таска, был доведен до принятия, но уже в период министерства Жана Тубона. 
la création du Haut comité3. À noter que Pompidou, hommes de lettres de formation et diplômé de l'École normale supérieure, était conscient des dangers qui menaçaient la langue française. Il anticipa également les conséquences que l'adhésion de la Grande-Bretagne à l'Union européenne aurait sur le statut du français comme langue de communication internationale, et aborda même avec le Premier ministre britannique Edward Heath les questions relatives à la sélection des fonctionnaires francophones pour les institutions européennes et de l'utilisation des deux langues de travail. Pompidou justifiait sa préoccupation par le fait que l'anglais n'était pas seulement la langue de l'Angleterre à l'époque, mais surtout celle des États-Unis, ce qui pouvait entraîner une perte de l'identité européenne et sa subordination à la puissance d'outre-Atlantique ${ }^{4}$.

La création du Haut comité de défense et de promotion du français fut une réponse directe du Premier ministre au livre Parlez-vous franglais ? de René Étiemble, écrivain et linguiste français, camarade de classe de Pompidou à l'École normale 5 .

Le comité fut suivi de commissions terminologiques dont la tâche consistait à choisir soit des termes pour désigner des réalités nouvelles, soit des équivalents français pour les emprunts indésirables dans l'intention de purifier la langue'. Ce faisant, le gouvernement exprimait son intention de combattre une autre langue, sous-entendu, évidemment, l'anglais, source de la plupart des emprunts.

La première loi française fut adoptée sous le président Valéry Giscard d'Estaing, connu pour ses dispositions pro-anglais. La loi 75-1349 sur l'usage du français, plus connue sous le nom de loi Bas-Lauriol, fut signée le 31 décembre 1975. L'idée du projet de loi venait du député Pierre Bas qui le présenta en mai 1973, et en juin de la même année, un autre député, Marc Lauriol, rédigea un rapport sur le sujet. L'examen du projet de loi dût être reporté en raison du décès de Georges Pompidou, de sorte qu'il fut donc signé par le nouveau président.

La loi Bas-Lauriol avait deux objectifs principaux : premièrement, protéger les intérêts des consommateurs, et deuxièmement, préserver l'unité linguistique, perçue comme patrimoine national et culturel. Cependant, les mesures restrictives introduites par cette loi dans l'esprit du purisme linguistique étaient quelque peu contraires aux idées de liberté et d'intérêts des consommateurs. En conséquence, les auteurs de la loi furent accusés de manifestations malvenues de nationalisme linguistique et de désir excessif de contrôler la langue. Par la suite, la loi fut oubliée et ne fut pratiquement plus appliquée. Toutefois, rétrospectivement, de nombreux chercheurs considèrent qu'il s'agissait d'une mesure suffisamment rationnelle pour protéger les travailleurs et les consommateurs?.

Sous la présidence de François Mitterrand, un groupe actif de députés se constitua pour améliorer la loi Bas-Lauriol et en particulier en élargir le champ d'application. De nombreux projets de loi furent présentés, dont un seul, préparé par la ministre de la Culture Catherine Tasca, alla jusqu'à l'adoption, mais alors que le ministre était Jacques Toubon, dont elle reçut le nom.

En 1984, le Comité supérieur de la langue française fut remplacé par le Commissariat général à la langue française et le Comité consultatif de la langue française. Ce nouveau comité devait développer diverses initiatives en faveur de l'emploi et la diffusion de la langue française. Le Comité consultatif de la langue française avait pour mission d'améliorer l'efficacité de l'action de l'État en matière de politique linguistique, notamment dans le domaine de la terminologie. 


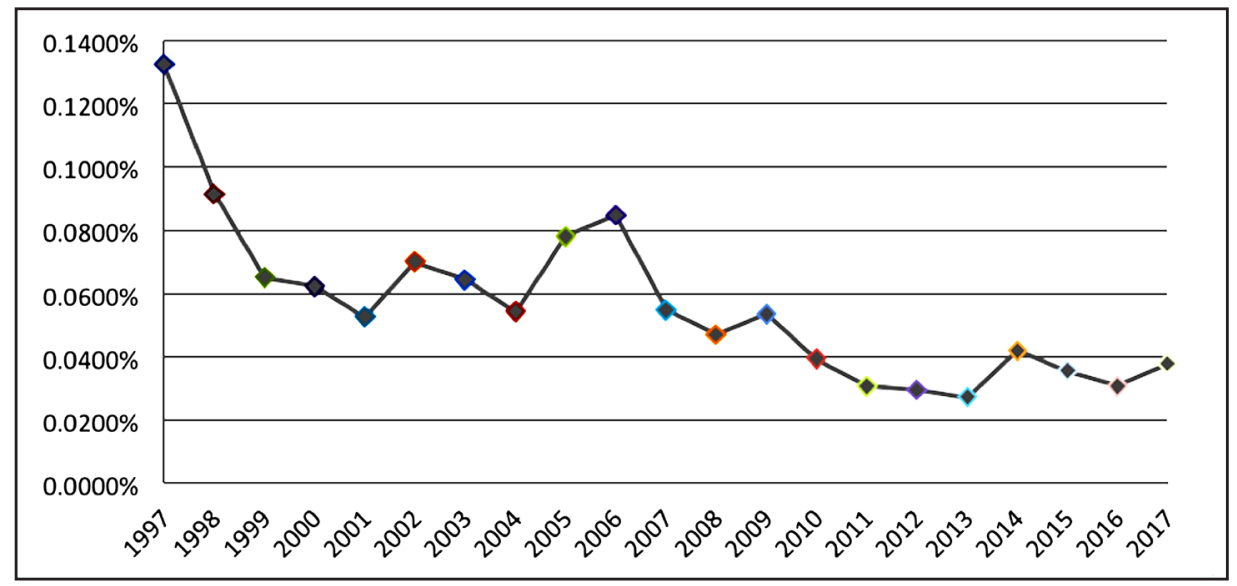

Рисунок 1. Изменение количества упоминаний закона Тубона в докладах DGLFLF за 1997-2017 гг.

Graphique 1. Évolution du nombre de références à la loi Toubon dans les rapports de la DGLFLF entre 1997 et 2017.

В 1984 г. на место Высшего комитета пришел Генеральный комиссариат по французскому языку (Commissariat général à la langue française) и Консультативный комитет по французскому языку (Comité consultatif de la langue française). Этот новый комитет должен был разрабатывать различные инициативы в области использования и распространения французского языка. Задача Комиссариата заключалась в том, чтобы повысить уровень эффективности действий государства в языковой политике, в частности в сфере терминологии.

В 1996 г. было создано Национальное управление по продвижению французского языка (DGLF), первым руководителем которой стал крупнейший французский лин-

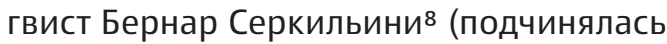
министру культуры). Уже в 2001 г. она была переименована в Национальное управление по продвижению французского языка и языков Франции (DGLFLF) в результате публикации произведшего эффект разорвавшейся бомбы доклада Серкильини о языках Франции. Из него французы узнали, что Франция не является моноязычной страной и в ней используются не менее 75 автохтонных региональных языков (не считая иммигрантских) ${ }^{9}$. Ежегодные доклады Генеральной делегации парламенту, обсуждаемые на совместном заседании обеих палат французского парламента, являются ценнейшим источником информации о языковой ситуации и о реальной языковой политике Франции.

Все доклады с 1997 по 2017 гг. были проанализированы с помощью программного комплекса для лексико-семантического анализа текстов T-Lab. B нем каждый ежегодный доклад представляется в виде корпуса, на основе которого составляется лемматизированный частотный словарь каждого текста и могут быть получены карты ассоциативных связей любой лексической единицы, используемой в этих текстах.

Уже при первом чтении всех докладов в хронологическом порядке сложилось впечатление, что в исследуемом временном диапазоне произошло изменение отношения к закону Тубона. Это субъективное впечатление было подкреплено объективными результатами изменения числа его упоминаний (в разных формулировках: Закон Тубона, Закон от 4 августа 1994 г., Закон об использовании французского языка и т.д.) (см. рис. 1). На рисунке 1 видно, что с 2006 г. начинается 
Puis, en 1996, la Délégation générale à la langue française (DGLF) fut créée sous l'autorité du ministre de la Culture, avec comme premier délégué général Bernard Cerquiglinis ${ }^{8}$ éminent linguiste français.

Mais dès 2001, elle fut rebaptisée Délégation générale aux langues françaises et aux langues de France (DGLFLF), après la publication, qui fit l'effet d'une bombe, du rapport de Bernard Cerquiglini sur les langues de France et qui apprit aux Français que la France n'était pas du tout un pays monolingue et qu'elle utilisait au moins 75 langues régionales autochtones (sans compter celles des immigrés)9.

Les rapports annuels de la délégation générale au Parlement, discutés lors d'une session conjointe des deux chambres du Parlement français, sont une source précieuse d'informations sur la situation et la politique linguistiques réelles de la France.

Tous les rapports de 1997 à 2017 ont été analysés à l'aide du logiciel T-Lab d'analyse lexico-sémantique des textes, dans lequel chaque rapport annuel est présenté dans un corpus sur la base duquel un dictionnaire de fréquences lemmatisées de chaque texte est compilé et des cartes des liens associatifs de toute unité lexicale utilisée dans ces textes peuvent être obtenues.

Dès la première lecture de tous les rapports par ordre chronologique, on eut l'impression qu'il y avait un changement d'attitude à l'égard de la loi Toubon pendant la période étudiée. Cette impression subjective fut confirmée par les résultats objectifs de la modification du nombre de références à la loi de Toubon (dans différentes formulations : la loi Toubon, la loi du 4 août 1994, la loi sur l'emploi du français, etc. - voir graphique 1).

Le graphique 1 montre que depuis 2006 le nombre de références à la loi Toubon dans les textes des rapports initialement consacrés au respect de la loi, initialement appelés « Rapport au Parlement sur l'application de la loi du 4 août 1994 relative à l'emploi de la langue française », a progressivement diminué.

Mais dès 2002, le nom des rapports a disparu et la loi Toubon n'a plus été mentionnée : ils étaient désignés comme « Rapport au Parlement sur l'emploi de la langue française $"$.

Cela amène à penser qu'entre 2006 et 2010, certains événements ont pu avoir un impact significatif sur la politique linguistique française.

C'est en 2007 que la politique linguistique française connut un changement radical dans son vecteur réel (mais pas déclaré) après l'élection à la présidence de Nicolas Sarkozy, connu pour ses dispositions d'esprit pro-américaines. Le président Sarkozy s'écarta des normes acceptées consistant à traiter le français comme un trésor national à protéger. Ce dont témoigne la ratification du protocole de Londres sur les brevets et les orientations de politique étrangère décrites dans le rapport de la commission spéciale intitulé La France et l'Europe dans le monde. Livre blanc sur la politique étrangère et européenne de la France 2008-2020.

Cette tendance ne fut en rien affectée par la politique du président français suivant, François Hollande. L'absence de mesures spécifiques proclamant le soutien à la langue française, ainsi que l'accent mis sur les langues régionales, entraîna une baisse continue du nombre de références à la loi Toubon dans les rapports sur l'usage de la langue française.

La France, malgré l'existence d'un instrument législatif pour protéger la langue française, ne peut plus ignorer les processus de mondialisation en cours dans le 
постепенное снижение количества упоминаний закона Тубона в текстах докладов, изначально посвященных именно соблюдению этого закона и именуемых Rapport au Parlement sur l'application de la loi du 4 août 1994 relative à l'emploi de la langue française (отметим, что с 2002 г. из названия докладов исчезло упоминание о законе Тубона: они стали именоваться Rapport au Parlement sur l'emploi de la langue française).

Это позволяет предположить, что в период между 2006 и 2010 гг. могли произойти какие-то события, значительно повлиявшие на языковую политику Франции. Именно в 2007 г. французская языковая политика претерпела резкое изменение своего реального (а не провозглашаемого) вектора после избрания президентом страны Николя Саркози, известного своими проамериканскими настроениями. Президент Саркози отошел от принятых стандартов отношения к французскому языку как к национальному достоянию, которое необходимо защищать. Об этом говорят и ратификация Лондонского протокола о патентах, и направления внешней политики, описанные в докладе специальной комиссии «Франция и Европа в мире. Белая книга по внешней и европейской политике Франции 2008-2020» (La France et l'Europe dans le monde. Livre blanc sur la politique étrangère et européenne de la France 2008-2020).

На данную тенденцию никак не повлияла и политика следующего французского Президента Франсуа Олланда. Отсутствие конкретных мер декларируемой поддержки французского языка, а также переключение внимания на поддержку региональных языков приводят к тому, что число упоминаний закона Тубона в докладах об использовании французского языка продолжает падать. Франция, несмотря на наличие законодательного инструмента защиты французского языка, больше не может не учитывать происходящие в мире процессы глобализации и не пересматривать позицию исключительности французского в пользу региональных языков, голоса защитников которых раздаются все громче в самобытных французских регионах. В новую, измененную парадигму французской языковой политики вписывается и принятый в 2013 г. Закон о высшем образовании и научных исследованиях (известный как закон Фиоразо, по имени министра высшего образования и научных исследований), разрешивший французским университетам реализовывать образовательные программы на английском языке ${ }^{10}$.

Для того чтобы отслеживать эволюцию языковой политики в отношении французского и английского языков, используются карты ассоциативных связей соответствующих лексем в докладах Национального управления по продвижению французского языка и языков Франции за 1997-2017 гг. (см. рис. 2, 3). Если проанализировать эти карты в хронологическом порядке, можно отчетливо увидеть процесс «одомашнивания» английского языка, который из одного из иностранных языков превращается во второй язык, все больше изучаемый и используемый в таких сферах коммуникации, как государственное управление, связи с Европейским союзом, наука, бизнес, торговля и образование.

Отметим, что именно членство в Европейском союзе во многом способствует изменению языковой политики Франции в сторону многоязычия, поддержки региональных языков и открытости английскому языку и переводам. Однако этот процесс тормозится в силу несоответствия французского законодательства, в том числе закона Тубона, нормам и принципам европейского права, что выливается в строгие замечания от Еврокомиссии.

Тезис о том, что Франция вынужденно изменила вектор своей языковой политики с защиты государственного языка на открытость как региональным, так и иностранным языкам, уже был высказан неоднократно. Показательным с этой точки зрения является позиция Франции в области терминологии 
monde et ne peut plus reconsidérer sa position d'exclusivité française en faveur des langues régionales dont les voix des défenseurs se font de plus en plus entendre dans les régions françaises distinctes.

Le nouveau paradigme modifié de la politique linguistique française s'inscrit également dans la loi adoptée en 2013 sur l'enseignement supérieur et la recherche scientifique (dite loi Fioraso, du nom de la ministre de l'Enseignement supérieur et de la Recherche scientifique) qui permet aux universités françaises de mettre en place des programmes d'enseignement en anglais ${ }^{10}$.

Le rapport de 2007 notait par exemple que le nombre croissant de traductions dans l'administration publique était un « signe d'administration moderne » en raison de l'intégration européenne et de la mondialisation.

Il est intéressant de noter que ces mots figurent dans les rapports de 2006 et 2007, lorsque le nombre de références à la loi Toubon commence à diminuer.

L'évolution des politiques linguistiques française et anglaise est suivie à l'aide de cartes des associations de lexèmes respectifs utilisés dans les rapports 19972017 de la Délégation générale à la langue française et aux langues françaises. Si l'on analyse ces cartes par ordre chronologique, on peut clairement voir le processus de « domestication » de l'anglais, qui passe du statut de langue étrangère à celui de deuxième langue de plus en plus étudiée et utilisée dans des domaines de communication tels que l'administration publique, les relations avec l'Union européenne, la science, les affaires, le commerce et l'enseignement.

La thèse selon laquelle la France a dû changer d'orientation politique linguistique, passant de la protection de la langue d'État à l'ouverture aux langues régionales et étrangères, a déjà été énoncée précédemment dans des sources universitaires.

La position de la France en matière de terminologie et de néologie en est une illustration. Historiquement, à partir de François Malherbe (1555-1628), la politique linguistique française a été dominée par la doctrine du purisme basée sur des interdictions. L'Académie française, fondée en 1634, a poursuivi cette politique pendant deux cent cinquante ans, ce qui a conduit à la séparation de la langue littéraire de la langue populaire et à un appauvrissement manifeste de la langue.

Toute révolution, qu'elle soit sociale ou technique, implique une révolution lexicale et l'émergence massive de néologismes comme principaux facteurs de la révolution linguistique. L'histoire de la langue française a connu des périodes d'enrichissement rapide sous l'influence de processus sociaux - au XVle et à la fin du XVIIIe -, une période de stagnation lexicale - au XVIIe siècle - et une période d'introduction active mais incontrôlée de nouveaux concepts associés à la nouvelle étape de la révolution scientifique et technique à partir de la seconde moitié du XXe siècle.

Cela a conduit à la création en 1996, par décret du ministre de la Culture, d'un dispositif étatique de contrôle et d'enrichissement de la langue française dans le domaine de la terminologie et des néologismes scientifiques et techniques ${ }^{11}$. Des commissions terminologiques ont été mises en place dans tous les ministères pour proposer des équivalents français des nouveaux concepts apparaissant dans les langues étrangères. Une fois publiés au Journal officiel, les nouveaux termes doivent être utilisés à la place des termes étrangers. Le contrôle de l'emploi 


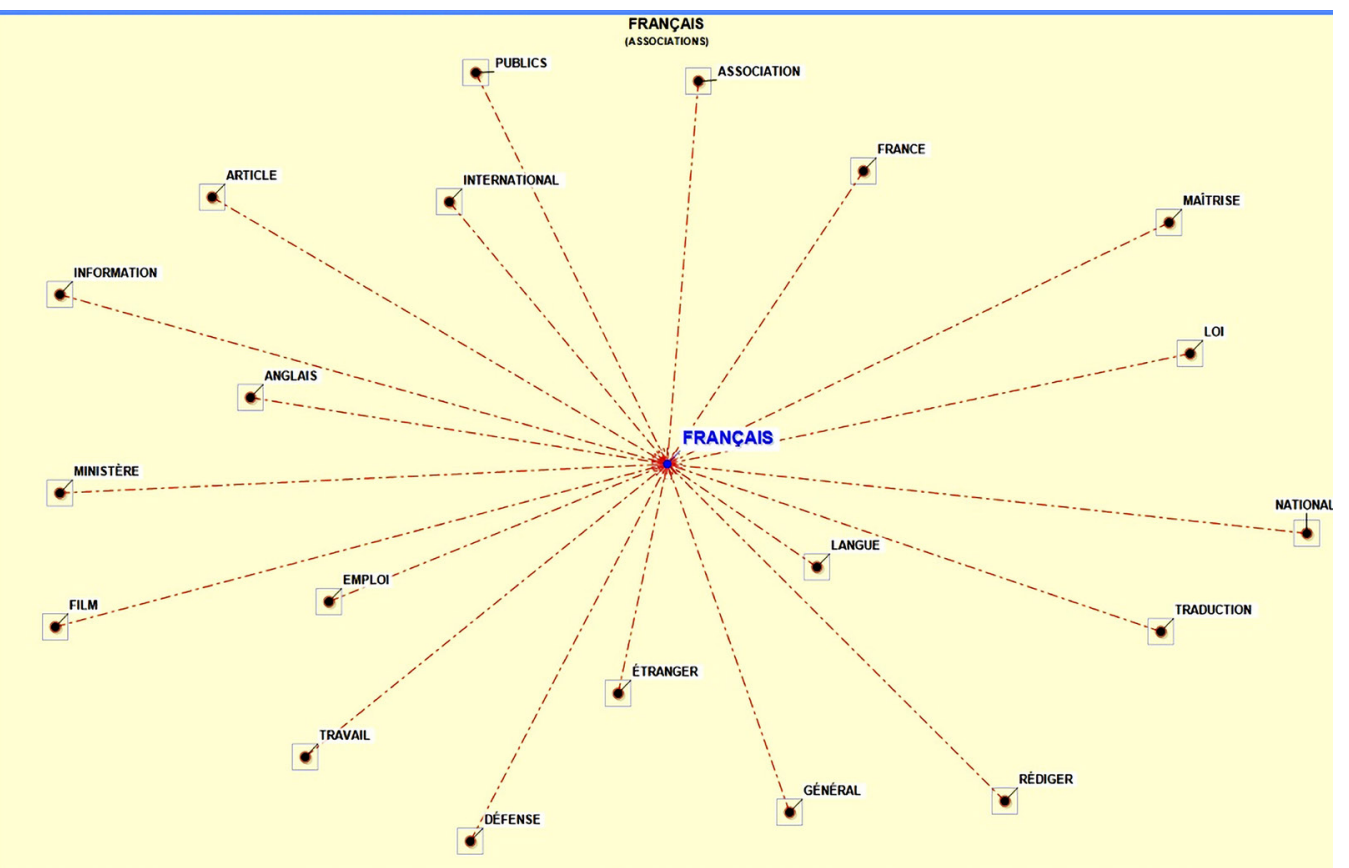

Рисунок 2. Карта ассоциативных связей лексемы le françаis в отчете DGLFLF за 2000 г.

Graphique 2. Carte des liens d'association du lexème le français dans le rapport de la DGLFLF pour 2000.

и неологии. Исторически, начиная с Франсуа Малерба (1555-1628), во французской языковой политике доминирующей была доктрина пуризма, основанная на запретах. Французская академия, основанная в 1634 г., продолжала эту политику на протяжении двухсот пятидесяти лет, что привело к отрыву литературного языка от народного и к очевидному обеднению языка.

Любая революция, социальная или техническая, влечет за собой лексическую революцию и массовое появление неологизмов как главных факторов языковой революции. История французского языка знала периоды бурного обогащения под влиянием социальных процессов - XVI и конец XVIII вв., период лексического застоя - XVII в. и период активного, но бесконтрольного внедрения новых понятий, связанных с новым этапом научно-технической революции, - со второй половины XX в.
Это привело к тому, что в 1996 г. декретом министра культуры был создан государственный механизм контроля и обогащения французского языка в области научно-технической терминологии и неологизмов ${ }^{11}$. Во всех министерствах были образованы терминологические комиссии, задачей которых было предложение французских эквивалентов новых понятий, появляющихся в иностранных языках. После публикации в Официальном бюллетене (Journal officiel) новые термины в обязательном порядке должны были употребляться вместо иностранных. Контроль за использованием новых терминов возлагался на Главную комиссию по терминологии и неологизмам, председателем которой был назначен президент Терминологического общества Франции профессор Лоик Депекер. В 2015 г. эта организация была переименована в Комиссию по обогащению французского 


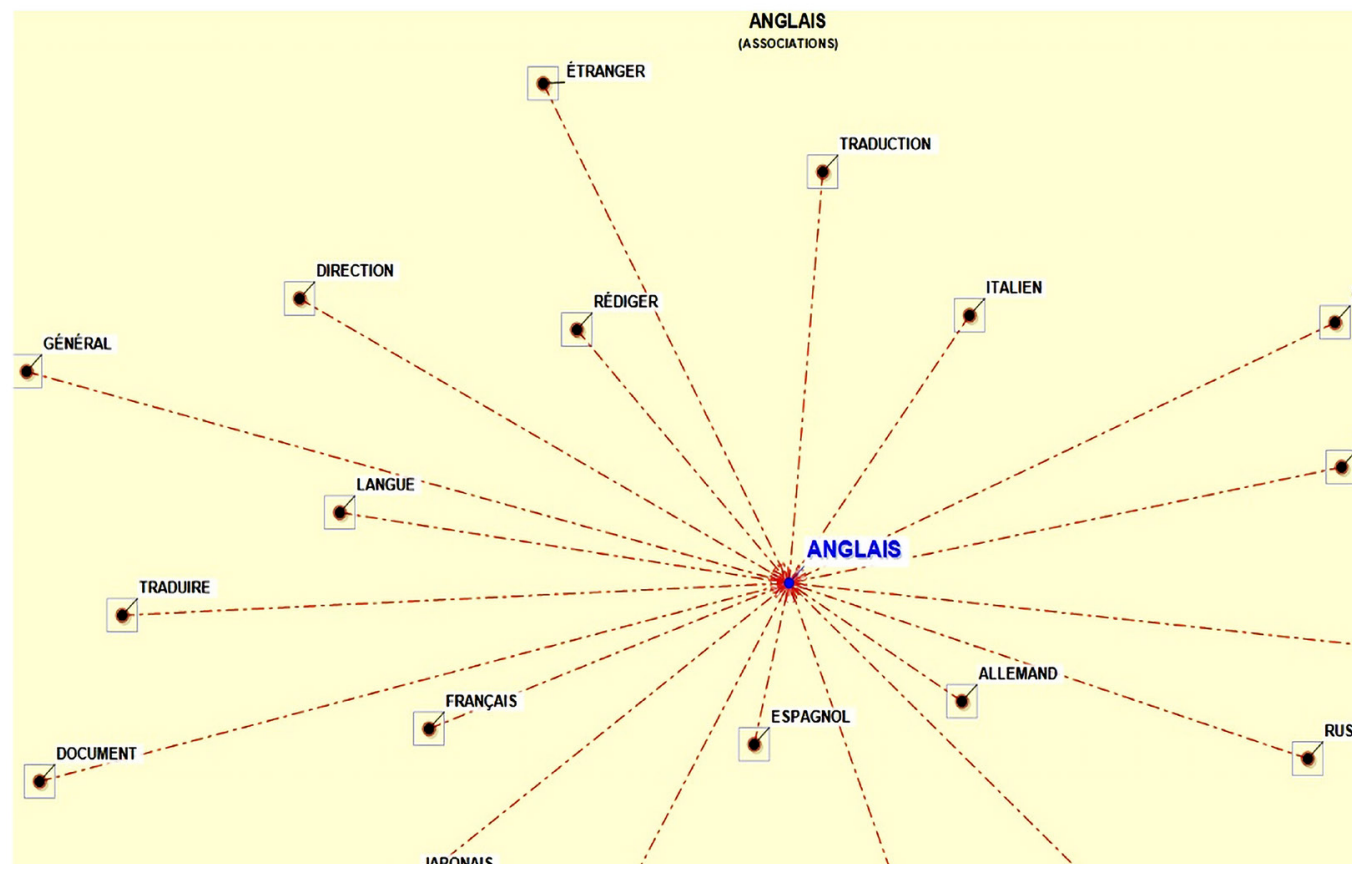

Рисунок 3. Карта ассоциативных связей лексемы l'anglais в докладе DGLFLF за 2000 г.

Graphique 3. Carte des liens d'association du lexème l'anglais dans le rapport de la DGLFLF pour 2000.

des nouveaux termes a été confié à la commission principale de terminologie et des néologismes, présidée par le professeur Loïc Depecker, président de la Société française de terminologie. En 2015, cette commission a été rebaptisée Commission pour l'enrichissement de la langue française. Le secrétaire perpétuel de l'Académie française est membre obligatoire de cette commission. La Commission publie plus de 200 nouveaux équivalents par an.

Sous les auspices de l'Association française de normalisation (équivalent français du Rosstandart russe), le comité technique TC37 de normalisation de la méthodologie de recherche en terminologie a été créé. Sa mission était de mettre en place un ensemble de normes méthodologiques applicables à différentes langues, ce qui est particulièrement important pour les multinationales. (En URSS, les analogues de ces organisations étaient la Commission de terminologie scientifique et technique de l'Académie des sciences de l'URSS et la Commission de terminologie du Gosstandart de l'URSS, dissoute pendant la perestroïka, prétendument par manque de nécessité).

En résumé, nous pouvons affirmer que la politique linguistique de la France tout au long de son histoire, sous l'influence des changements sociaux, politiques et économiques, a modifié à plusieurs reprises le vecteur de son développement, en commençant par le purisme et l'interdiction d'utiliser des emprunts étrangers et en le remplaçant par une politique contrôlée d'enrichissement de la langue 
языка. Обязательным ее членом является и терминологическая комиссия Госстандарпостоянный секретарь Французской ака- та СССР, распущенные в годы перестройки демии. Ежегодно Комиссия публикует бо- якобы за ненадобностью.) лее 200 новых эквивалентов.

При Французской ассоциации по нормализации (Association française de normalisation аналог российского Росстандарта) был создан технический комитет ТС37 по стандартизации методологии терминологических исследований. Его задачей было создание корпуса методологических стандартов, применимых к разным языкам, что особенно важно для транснациональных корпораций. (В СССР аналогами этих организаций были Комиссия по научно-технической терминологии Академии наук СССР
Подводя итог, можно констатировать, что языковая политика Франции на всем протяжении своей истории под влиянием социальных, политических и экономи ческих изменений неоднократно меняла вектор своего развития, начав с пуризма и запрета на использование иностранных заимствований и сменив его на контролируемую политику обогащения французского языка путем создания французских эквивалентов новых понятий, заимствуемых в основном из стран англосаксонского языкового ареала.

\section{Примечания}

${ }^{1}$ Hagège C. Encyclopédie de l'Agora. Режим доступа: http://agora.qc.ca/dossiers/Claude_ Hagege (дата обращения: 11.11.2019)

2 См., напр.: Марусенко М.А. Языковая политика Франции. СПб.: Изд-во СПбГУ, 2011.

3 Historique - Langue française et langues de France. Ministère de la Culture et de la Communication. Режим доступа: http://www.culturecommunication.gouv.fr/ Politiques-ministerielles/Langue-francaise-et-langues-de-France/La-DGLFLF/ Historique (дата обращения: 02.12.2019).

4 Deniau J.-F. (2004) Down with Amerilish! The Guardian. April, 5. Режим доступа: http://www. theguardian.com/world/2004/apr/05/france.features114 (дата обращения: 01.12.2019).

5 Saint-Robert Ph. De Gaulle, la langue française et la francophonie. Encyclopédie de la Francophonie. Режим доступа: http://agora-2.org/francophonie.nsf/Documents/ Charles_de_Gaulle-De_Gaulle_la_langue_francaise_et_la_francophonie_par_ Philippe_de_Saint_Robērt (дата обращения: 02.10.2019).

${ }^{6}$ Décret $n^{\circ}$ 72-19 du 7 janvier 1972 relatif à l'enrichissement de la langue française // Légifrance. URL : https://www.legifrance.gouv.fr/jo_pdf.do?id=JORFTEXT000000879206 (date de consultation : 25.11.2019).

7 Chansou M., Politique de la langue et idéologie en français contemporain, Mots, 1983/ Vol/6/ n 1. p. 59-77. Op.cit. p. 29-32.

8 Historique - Langue française et langues de France, ministère de la Culture et de la Communication. URL : http://www.culturecommunication.gouv.fr/Politiquesministerielles/Langue-francaise-et-langues-de-France/La-DGLFLF/Historique (date de consultation : 02.12.2019).

9 Cerquiglini B., Les langues de France, PUF, Paris, 2003, 368 p.

10 Loi relative à l'enseignement supérieur et à la recherche : https://www.legifrance.gouv. fr/affichLoiPreparation.do?idDocument=JORFDOLE000027197524\&type=general.

11 Décret № 96-602 du 3 juillet 1966 relatif à l'enrichissement de la langue française, Journal officiel de la République française, 5 juillet 1996. 
française par la création d'équivalents français de nouveaux concepts empruntés principalement aux pays de l'espace linguistique anglo-saxon.

Pour conclure, la politique linguistique française, tout au long de son histoire, influencée par les changements sociaux, politiques et économiques, a modifié à plusieurs reprises son vecteur de développement, en commençant par le purisme et l'interdiction des emprunts étrangers pour le remplacer par une politique contrôlée d'enrichissement de la langue française en créant des équivalents français aux nouveaux concepts empruntés principalement aux pays de l'espace linguistique anglo-saxon.

\section{Remarques}

${ }^{1}$ Hagège C., Encyclopédie de l'Agora. URL : http://agora.qc.ca/dossiers/ Claude_Hagege (date de consultation : 11.11.2019).

2 Maroussenko M.A., La politique linguistique de la France, éd. de l'Université de Saint-Pétersbourg SPBGU, 2011, 624 p.

3 Historique - Langue française et langues de France, ministère de la Culture et de la Communication. URL : http://www.culturecommunication.gouv. fr/Politiques-ministerielles/Langue-francaise-et-langues-de-France/LaDGLFLF/Historique (date de consultation : 02.12.2019).

4 Deniau J.-F., Down with Amerilish!, The Guardian, 05.04.2004. URL : http:// www.theguardian.com/world/2004/apr/05/france.featuresl14 (date de consultation : 01.12.2019).

5 Saint-Robert Ph. de, De Gaulle, la langue française et la francophonie, Encyclopédie de la Francophonie. URL : http://agora-2.org/francophonie. nsf/Documents/Charles_de_Gaulle-De_Gaulle_la_langue_francaise_et_ la_francophonie_par_Philippe_de_Saint_Robert (date de consultation : 02.10.2019).

${ }^{6}$ Décret $n^{\circ} 72-19$ du 7 janvier 1972 relatif à l'enrichissement de la langue française // Légifrance. URL : https://www.legifrance.gouv.fr/jo_pdf. do?id=JORFTEXT000000879206 (date de consultation : 25.11.2019).

7 Chansou M., Politique de la langue et idéologie en français contemporain, Mots, 1983/ Vol/ 6/ n 1. p. 59-77. Op.cit. p. 29-32.

8 Historique - Langue française et langues de France, ministère de la Culture et de la Communication. URL : http://www.culturecommunication.gouv. $\mathrm{fr} /$ Politiques-ministerielles/Langue-francaise-et-langues-de-France/LaDGLFLF/Historique (date de consultation : 02.12.2019).

${ }^{9}$ Cerquiglini B., Les langues de France, PUF, Paris, 2003, 368 p.

10 Loi relative à l'enseignement supérieur et à la recherche : https://www. legifrance.gouv.fr/affichLoiPreparation.do?idDocument=JORFDOLE00002 7197524\&type=general.

11 Décret № 96-602 du 3 juillet 1966 relatif à l'enrichissement de la langue française, Journal officiel de la République française, 5 juillet 1996. 